GLOBAL HEALTH

\title{
State of the world's children: life beyond survival B O Olusanya
}

Arch Dis Child 2005;90:317-318. doi: 10.1136/adc.2004.062240

$\mathrm{T}$ he inauguration of a global child health section in Archives in May 2004 heralded a unique platform for scientists, public health managers, and multilateral agencies to address the spate of intractable health and social issues confronting today's child in the developing world. The maiden contribution in Archives aptly reviewed the role of poverty, infectious diseases, and malnutrition on the unsatisfactory under-5 mortality rates in developing countries. ${ }^{1}$ It also re-echoed the prevailing inequality and inequity in global child health as elucidated by the Bellagio Study Group. ${ }^{2}$ About half of the 10.8 million child deaths in year 2000 worldwide occurred in India, Nigeria, China, Pakistan, Democratic Republic of Congo, and Ethiopia, although these countries were not necessarily the worst by infant mortality rate ranking. That two thirds of these deaths were preventable by child survival interventions that are currently available and feasible in these countries was most disturbing. ${ }^{3}$ In addition, the world's 225 richest individuals control a combined wealth equivalent to the annual income of the poorest 2.5 billion people, almost half of the world's population. ${ }^{14}$ Undoubtedly, these observations demanded urgent action.

Since the year 2000, multilateral groups like the Global Movement for Children (GMV) and the Global Alliance for Vaccines and Immunisation (GAVI) have collaborated with UNICEF and WHO to accelerate reduction in infant/childhood mortality rates. This momentum is crucial for realising the targeted two thirds reduction in mortality rates as outlined in the UN Millennium Development Goals. ${ }^{5}$ Slow but notable progress is evident from recent WHO/UNICEF reports in which a 35\% drop in measles deaths was recorded in 2002 for Africa, a region with almost 500000 measles deaths per year. ${ }^{6}$ In Nigeria, over $50 \%$ decline was reported between 2000 and 2002 in the incidence of measles, neonatal tetanus, tuberculosis, cerebrospinal meningitis, diphtheria, and pertussis. ${ }^{7}$ In Asia, similar improvement in mortality indices was not unlikely, but this is often masked or outstripped by the high annual growth in population.

\section{AN INEQUITY IN EQUALITY}

Survivors of infant/childhood mortality represent the vanguard of the nations' future socioeconomic development. Unfortunately, focus on this group has always been undermined by the exclusive and inequitable use of cause-of-death as the standard measure of child health status. This is corroborated by the lack of disability statistics in UNICEF's yearly report on the state of the world's children.

In the six countries accounting for over half of the annual global deaths (table 1), 55.9 million children lived beyond their first year in 2002. By the fifth year this number declined marginally by $3 \%$. Overcrowding, poor sanitation, malnutrition, lack of access to safe drinking water, and poverty characterise the living conditions in these countries. Many of these children are either born with chronic diseases and congenital anomalies or acquire disabling disorders from the attack and treatment of fatal illnesses such as measles, meningitis, and severe malaria. They are thus disadvantaged from early childhood in competing with their more healthy peers for life opportunities, and are unlikely to reach their full potential in their lifetime average of 55.8 years.

Generally, there is no provision for the management of childhood disabilities in healthcare services. Available social and educational services are also rudimentary and tend to alienate rather than integrate disabled children into the larger society. A child in a developing country may never undergo developmental assessment in the first three crucial years for early childhood development. Routine newborn or childhood screening does not exist among high risk groups for specific conditions for which early detection and intervention are necessary. For example, not less than 600000 babies are born with congenital deafness annually in developing countries. ${ }^{8}$ Current evidence suggests that if these babies were detected within three months of birth and provided with amplification within six months of life, they are likely to have linguistic, speech, and cognitive development comparable to their normal hearing peers. ${ }^{9}$ Yet physicians account for delays in diagnosis and intervention

Table 1 Survivors of childhood mortality in 2002 in countries accounting for over $50 \%$ of global child deaths*

\begin{tabular}{|c|c|c|c|c|c|c|c|c|}
\hline \multirow[b]{2}{*}{ Countries } & \multirow[b]{2}{*}{ Annual births } & \multirow{2}{*}{$\begin{array}{l}\text { Infant mortality } \\
\text { rate }\end{array}$} & \multirow{2}{*}{$\begin{array}{l}\text { Under } 5 \\
\text { mortality rate }\end{array}$} & \multirow[b]{2}{*}{ Infant deaths } & \multirow[b]{2}{*}{ Under 5 deaths } & \multicolumn{2}{|l|}{ Survivors } & \multirow{2}{*}{$\begin{array}{l}\text { Life expectancy at } \\
\text { birth (years) }\end{array}$} \\
\hline & & & & & & After first year & After fifth year & \\
\hline India & 25221000 & 67 & 93 & 1689807 & 2346000 & 23531193 & 22875000 & 64 \\
\hline Nigeria & 4764000 & 110 & 183 & 524040 & 872000 & 4239960 & 3892000 & 52 \\
\hline China & 18857000 & 31 & 39 & 584567 & 735000 & 18272433 & 18122000 & 71 \\
\hline Pakistan & 5415000 & 83 & 107 & 449445 & 579000 & 4965555 & 4836000 & 61 \\
\hline DR of Congo & 2594000 & 129 & 205 & 334626 & 532000 & 2259374 & 2062000 & 41 \\
\hline Ethiopia & 2948000 & 114 & 171 & 336072 & 504000 & 2611928 & 2444000 & 46 \\
\hline $\begin{array}{l}\text { All six } \\
\text { countries }\end{array}$ & 59799000 & 89 & 133 & 3918557 & 5568000 & 55880443 & 54231000 & 55.8 \\
\hline Global & 132787000 & 56 & 82 & 7436072 & 10889000 & 125350928 & 121898000 & 63 \\
\hline
\end{tabular}

Mortality rates are expressed per thousand live births.

*Data from State of the World's Children 2004, UNICEF. 
because they regard hearing impairment as non-life threatening and therefore insignificant. Unfavourable cultural beliefs towards disabilities also play no small role in limiting access to timely medical and educational intervention. The perception of congenital disabilities as punishment from a deity who must be appeased to reverse this infliction is not uncommon in rural communities. Even with the lowest life expectancy of 41 years (table 1 ), the psychological, social, and economic burden to families and the community is unquantifiable. It may be instructive to investigate the economics of keeping all babies alive (including those who are HIV infected) and habilitating those with disabilities.

\section{REVERSING INEQUITY IN HEALTH MEASUREMENT}

Ironically, the WHO's definition of health, as a state of complete physical, mental, and social wellbeing and not merely the absence of disease or infirmity is reflected in UNICEF's current five priorities, which emphasise early childhood development as an extension of its traditional focus on infant/childhood mortality. ${ }^{10}$ Unfortunately, there is still a paucity of credible global databases on childhood disabilities relative to those for mortality indices. The only UN database on disabilities (http://unstats.un.org/unsd/ disability/) cautions against using the information for crosscountry comparisons due to marked variations in concepts and methodologies as in most other surveys. ${ }^{11}$ The multidimensional nature of disabilities poses considerable challenge for epidemiologists as disability may originate from one or more of physical, neurodevelopmental, cognitive, and learning/behavioural disorders. It is easier to identify and classify a child as dead than one that is disabled. The evaluation and classification of the functional dimensions of child health was hampered for many years until the recent introduction of the International Classification of Functioning, Disability and Health (ICF) which has now provided a uniform framework for measuring health status in all age groups across the world's populations. ${ }^{12}$ For most developing countries already overwhelmed by the challenge of dealing with prevailing fatal and communicable diseases, there is a moral dilemma between child survival and wellbeing. A global action spearheaded by the UN agencies and their partners is needed to address this public health quagmire. The scientific community's contribution to this paradigm shift is equally imperative. The new Archives initiative is therefore a positive step in this direction, but requires a renaissance of an integrated and holistic approach to global child health advocacy. It is when we all share the conviction that "all who live, must live to thrive" can we really resolve today's moral dilemma and have a clearer picture of the state of the world's children beyond the survival agenda.

\section{Competing interests: none declared}

Correspondence to: Dr B O Olusanya, Academic Unit of Audiological Medicine, Institute of Child Health and Great Ormond Street Hospital for Children NHS Trust, 30 Guilford Street, London WCIN 1EH, UK;

b.olusanya@ich.ucl.ac.uk or boolusanya@aol.com

Accepted 31 July 2004

\section{REFERENCES}

1 Bhutta ZA. Beyond Bellagio: addressing the challenge of sustainable child health in developing countries. Arch Dis Child 2004;89:483-7.

2 Black RE, Morris SS, Bruce J. Where and why are 10 million children dying every year? Lancet 2003;361:2226-34.

3 Jones G, Steketee RW, Black RE, et al. How many child deaths can we prevent this year? Lancet 2003;362:65-71.

4 Waterston T. Inequity in child health as a global issue. Pediatrics 2003;112:739-41.

5 UN. General Assembly, 56th session. Road map towards the implementation of the United Nations millennium declaration: report of the Secretary-General. New York: United Nations, 2001.

6 Kapp C. WHO and UNICEF report good news on measles. Lancet 2004;363:1531.

7 Raufu A. Nigerian immunization programme sees results. BMJ 2003;326:121.

8 Olusanya BO, Luxon LM, Wirz SL. Benefits and challenges of newborn hearing screening for developing countries. Int J Pediatr Otorhinolaryngol 2004;68:287-305.

9 Yoshinaga-Itano C, Sedey AL, Coulter DK, et al. Language of early and lateridentified children with hearing loss. Pediatrics 1998;102:1161-71.

10 UNICEF. UNICEF's priorities for children 2002-2005 in UNICEF's mediumterm strategic plan (MTSP) for the period 2002-2005.

11 Durkin M. The epidemiology of developmental disabilities in low-income countries. Ment Retard Dev Disab 2002;8:206-11.

12 World Health Organisation. International Classification of Functioning, Disability and Health. Geneva: WHO, 2001

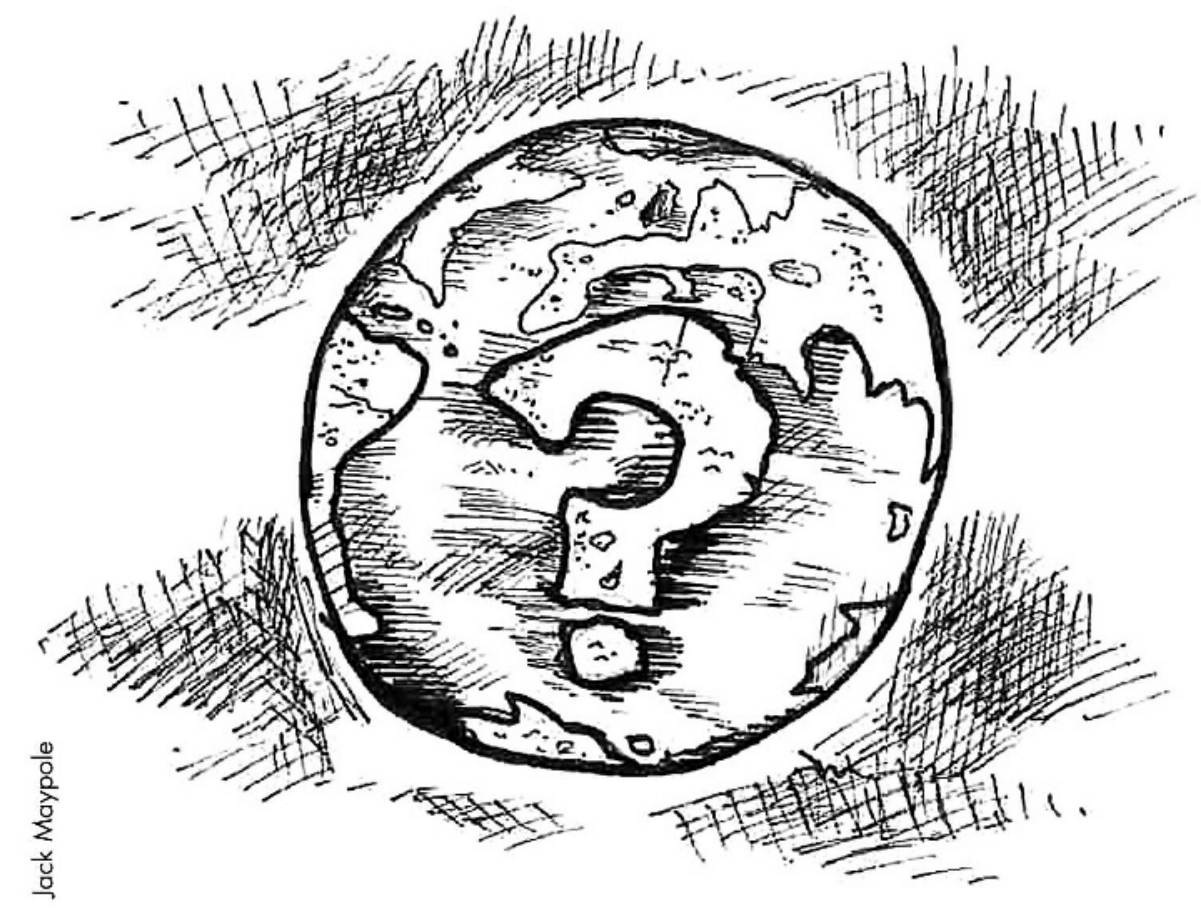

